\title{
BMJ Open A cross sectional study of surgical training among United Kingdom general practitioners with specialist interests in surgery
}

\author{
H J M Ferguson, ${ }^{1,2,3}$ J E F Fitzgerald, ${ }^{1,4,5}$ J Reilly, ${ }^{1,6}$ A J Beamish, ${ }^{1,7,8}$ \\ $\mathrm{V} \mathrm{J} \mathrm{Gokani,}{ }^{1,9}$ on behalf of the Council of the Association of Surgeons in Training
}

To cite: Ferguson HJM, Fitzgerald JEF, Reilly J, et al. A cross sectional study of surgical training among United Kingdom general practitioners with specialist interests in surgery. BMJ Open 2015;5:e007677. doi:10.1136/bmjopen-2015007677

- Prepublication history and additional material is available. To view please visit the journal (http://dx.doi.org/ 10.1136/bmjopen-2015007677).

Received 14 January 2015 Revised 12 March 2015 Accepted 18 March 2015

CrossMark

For numbered affiliations see end of article.

Correspondence to H J M Ferguson; fergusonh@doctors.org.uk

\section{ABSTRACT}

Objectives: Increasing numbers of minor surgical procedures are being performed in the community. In the UK, general practitioners (family medicine physicians) with a specialist interest (GPWSI) in surgery frequently undertake them. This shift has caused decreases in available cases for junior surgeons to gain and consolidate operative skills. This study evaluated GPwSl's case-load, procedural training and perceptions of offering formalised operative training experience to surgical trainees.

Design: Prospective, questionnaire-based crosssectional study.

Setting/participants: A novel, 13-item, selfadministered questionnaire was distributed to members of the Association of Surgeons in Primary Care (ASPC). A total 113 of 120 ASPC members completed the questionnaire, representing a $94 \%$ response rate. Respondents were general practitioners practising or intending to practice surgery in the community.

Results: Respondents performed a mean of 38 (range 5-150) surgical procedures per month in primary care. $37 \%(42 / 113)$ of respondents had previously been awarded Membership or Fellowship of a Surgical Royal College; 22\% (25/113) had completed a surgical certificate or diploma or undertaken a course of less than 1 year duration. $41 \%(46 / 113)$ had no formal British surgical qualifications. All respondents believed that surgical training in primary care could be valuable for surgical trainees, and the majority $(71 / 113,63 \%)$ felt that both general practice and surgical trainees could benefit equally from such training.

Conclusions: There is a significant volume of surgical procedures being undertaken in the community by general practitioners, with the capacity and appetite for training of prospective surgeons in this setting, providing appropriate standards are achieved and maintained, commensurate with current standards in secondary care. Surgical experience and training of GPwSl's in surgery is highly varied, and does not yet benefit from the quality assurance secondary care surgical training in the UK undergoes. The Royal Colleges of Surgery and General Practice are well placed to invest in such infrastructure to provide
Strengths and limitations of this study

- This article represents a novel UK-wide crosssectional study investigating surgical training within the community.

- The combined paper and online survey format, combined with a Continuing Professional Development (CPD) point incentive has resulted in a very high response rate, improving the reliability of the results.

- Responses to this voluntary survey are subjective, and potentially open to bias either in favour of operative experience, or indeed in hypothetical willingness to provide training, when financial implications have not been formulated.

- By surveying only the members of the Association of Surgeons in Primary Care (ASPC), data was not collected from consultant surgeons subcontracted to the community sector, nor those practitioners who are not members of ASPC. The respondents are self-selected and are likely to form a significant part of any future community surgical training resource. Doctors who have been consultants, and are now general practitioners, were, however, included.

- This paper opens the discussions in developing formal training and accreditation of community surgical trainers, and mechanisms to deliver high fidelity, quality assured training on a national scale.

long-term, high-quality service and training in the community.

\section{INTRODUCTION}

Health service reconfigurations are increasingly seeking to provide care in the community, closer to patients. ${ }^{1}$ Minor surgery is one area that has seen such a shift in practice: many minor procedures have already migrated to primary care. In the UK these are frequently undertaken by general practitioners (family 
medicine physicians) with a specialist interest (GPwSI) in surgery, with their caseload typically including vasectomies, carpal tunnel decompressions and excision biopsies of skin lesions and hernia repair. ${ }^{2}$ In some areas consultant surgeons work alongside GPwSI's in the community.

Advantages of this policy include improved access to care for patients, reduced waiting times and improved patient satisfaction. ${ }^{3}$ The clinical quality and costeffectiveness have been the subject of some debate with conflicting data, ${ }^{3-5}$ although high-quality practice has been reported. ${ }^{6} 7$

Although UK-specific data is lacking, international studies suggest that GP practices that performed more community surgery had a lower referral rate to secondary hospital care for some procedures. ${ }^{8}$ The tariffs charged for procedures in primary care is also often lower than those charged for hospital care, which may contribute to this migration of cases. The migration of these services means that there has been a consequent loss of minor operating within the hospital environment, leading to decreased opportunities for junior surgeons to practise basic surgical procedures. ${ }^{9}$

This study evaluated GPwSI's case-load, procedural training and perceptions of offering formalised operative training experience to surgical trainees.

\section{METHODS}

\section{Participants and setting}

GPwSIs are qualified generalist primary care doctors who undertake additional medical or surgical specialty work. ${ }^{10}{ }^{11}$ No national standardised process for attaining GPwSI status exists. Historically, regional Primary Care Trusts were responsible for accreditation and re-accreditation of GPwSIs in England. The Royal College of General Practitioners (RCGP) and NHS England are currently devising a new system in order to determine the knowledge, skills and competencies required across the range of different special interest areas.

The surgical training pathway in the UK has been described in detail previously. ${ }^{12}$ Surgical trainees rotate between hospitals and supervising consultants over the course of 8 years of specialist training. No formal placements or provision for surgical placements or training within the primary care community setting currently exists in the UK.

The Association of Surgeons in Training (ASiT) undertook the current study with assistance from the Association of Surgeons in Primary Care (ASPC). ASiT is a professional body and registered charity working to promote excellence in surgical training for the benefit of junior doctors and patients alike throughout the UK and Republic of Ireland. ASiT is independent of the National Health Service (NHS), UK Surgical Royal Colleges and surgical specialty associations.

The ASPC is a professional membership society providing support, training and professional development to those undertaking surgical procedures in the community setting. It plays a role in developing professional standards, liaises with professional and regulatory organisations including the Care Quality Commission and Clinical Commissioning Groups (CCGs), and represents members in negotiations affecting the provision of surgery in the community.

\section{Questionnaire design and distribution}

A novel 13-item, self-administered questionnaire survey was developed in order to evaluate the caseload of GPwSI's, procedural training, and perceptions regarding offering formalised operative training experience to surgical trainees. This consisted of open answer free text, multiple choice and 5-point Likert scale responses. A copy of the survey is provided as online supplementary information.

The ethical dimensions of this non-mandatory evaluation survey were considered and no concerns were identified. Completion of the questionnaire by ASPC members was taken as implied consent to participate in this study. The questionnaire was reviewed by the ASPC prior to distribution and permission was granted to undertake this survey among their members.

All GPwSI delegates at the 2013 ASPC annual conference were provided with copies of the survey form. A SurveyMonkey (Palo Alto, California, USA) link to the online version of the survey was also sent to all members of the ASPC. Delegates were awarded one Continuing Professional Development (CPD) point by the ASPC for completing the questionnaire. Duplicate online and paper responses were excluded.

\section{Data analysis}

Paper questionnaires were transcribed to Microsoft Excel (Microsoft, 2010, Redmond, Washington, USA), which was used to calculate descriptive statistics. Statistical analysis was performed using SPSS V.20 (SPSS Inc, 2012, Chicago, Illinois, USA) and statistical significance was accepted at $\mathrm{p}<0.05$. Significance testing was performed using the $\chi^{2}$ test for non-parametric binary data.

\section{RESULTS}

Of 105 delegates attending the ASPC conference, 65 $(62 \%)$ fully completed the questionnaire and were entered into the analysis. All were GP's or GPwSI's. A further 50 complete responses were obtained from the online survey. Two duplicates of paper questionnaires were excluded, giving a total of 113 completed responses entered into the analysis. Of the total membership of the ASPC of 120, this represents $94 \%$ of members. No consultant surgeons subcontracted to work in the community completed the survey, but three respondents had previously worked in the UK as NHS surgical consultants.

Respondents performed a mean of 38 surgical procedures per month (range 5-150). The most common procedure performed in primary care was vasectomy 
Table 1 Procedures undertaken in primary care and the proportion of respondents undertaking them

\begin{tabular}{ll}
\hline Surgical procedure & $\begin{array}{l}\text { Respondents performing } \\
\text { this procedure (\%) }\end{array}$ \\
\hline Vasectomy & 78 \\
Excision biopsies of lumps & 65 \\
and bumps or skin lesions & \\
Surgery for ingrowing toenail & 19 \\
Carpal tunnel decompression & 12 \\
Joint injections & 5 \\
Circumcision & 3 \\
Gl endoscopy & 3 \\
Ganglion surgery & 3 \\
Rubber band ligation of & 3 \\
haemorrhoids & \\
Hernia repair & $<1$ \\
Flexible nasoendoscopy & $<1$ \\
\hline
\end{tabular}

(88/113, $78 \%$ of respondents), followed by minor skin surgery $(73 / 113,65 \%)$. A further breakdown of procedural volume is provided in table 1 .

All respondents believed that surgical training in primary care could be a valuable resource, and the majority $(71 / 113,63 \%)$ felt that both GP and surgical trainees could benefit equally from such training, with 27\% (31/113) feeling GP trainees would benefit most and $7 \%(8 / 113)$ surgical trainees most. While most felt competent to train Foundation Programme (91/113, $81 \%)$ or Core Surgical Training $(90 / 113,80 \%)$ trainees, fewer felt competent to train those in Higher Surgical Training programmes at levels ST3-4 $(65 / 113,58 \%)$ or ST5-8 (45/113, 41\%), respectively, $(\mathrm{p}=0.0011)$.

All but two respondents felt able to train others in at least one defined surgical procedure, most frequently vasectomy $(44 / 113,38 \%)$ and excision of lumps and bumps' $(45 / 113,39 \%)$. Three-quarters of respondents suggested that they would be prepared to commit $\geq 25 \%$ of their lists to training, in return for professional recognition $(77 / 113,68 \%)$ and/or additional remuneration $(73 / 113,65 \%)$.

In terms of prior formal surgical training, $37 \%$ (42/113) of respondents had been awarded either membership or fellowship of a surgical Royal College, 22\% (25/113) had completed a surgical postgraduate certificate or diploma, or undertaken a course of less than 1-year duration, while $41 \%(46 / 113)$ had no formal surgical qualifications (figure 1). Half of respondents gained their training in approved surgical training posts, while the remainder learnt them as either a GP trainee or a principle GP.

Representative examples of free-text comments are provided in box 1 .

\section{DISCUSSION}

This novel study is the first to explore the potential for providing basic surgical training within the community

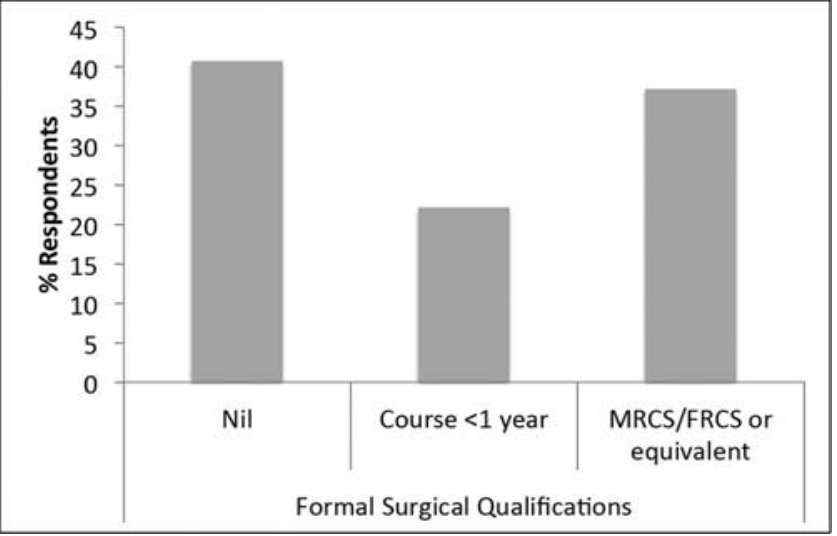

Figure 1 Formal surgical qualifications among respondents.

setting, and suggests both opportunities and concerns in providing this. Significant numbers of surgical procedures are already being performed in the community both by GPwSI's and consultant surgeons subcontracted

\section{Box 1 Qualitative comments from respondents}

- "Hospital and community settings are completely different things:

- Hospital-technical expertise; dealing with complaints; understanding hospital systems/process; advanced techniques/equipment; access to latest information/research; career advancing

- Community-volume; holistic; patient journey; better patient communication; different viewpoint; tutor less eccentric/aggressive!; not really career enhancing"

- "In my view surgical training has deteriorated in the last 5 years. There is therefore a need to provide training opportunities in community and hospital sites. [Surgical trainees] would benefit from the community experience."

- "The European Working Time Directive has led to low levels of experience in surgical trainees long into their training. Traditionally surgeons in training who convert to general practice do 5-10 years post qualification and the skill level at this stage is falling to the point that few GPWSI will be created from this route."

- "I now run a Diploma in Minor Surgery—we need to align it with surgical training (or vice versa)."

- "Myself and colleagues are currently mentored by secondary care consultants in all of our procedures. Further integration with surgical training would benefit both camps".

- "The relationship between consultants, trainees and community surgeons must begin at the early trainee level."

- "This puts patients and their needs above administration."

- "Two issues:

1. Remuneration for the invariable slowing down of clinic lists when we 'hands-on' train the procedure

2. Malpractice/indemnity issues.

Both require government involvement. The time investment will be paid off in cost savings by moving procedures out of hospitals."

- "I used to train ST1/2 as a staff surgeon. Training is not a new field for me."

"I'm not sure l'd be happy to become a trainer. Sorry!" 
into community centres. This is in keeping with a political drive to blur the primary and secondary care interface, started by Lord Ara Darzi's review of the NHS in $2008,{ }^{13}$ and now epitomised by the Shape of Training Review. ${ }^{14}$ Patient groups have also expressed a desire to receive more treatment closer to home. ${ }^{3}$

Limitations of this survey include the delivery to only the members of the ASPC, which effectively excludes gaining data from the unquantifiable number of nonmembers, and consultant surgeons subcontracted to the community sector. These specialists may form a significant part of any future community surgical training resource, but as they do not form part of this data, this section of community surgery providers cannot be commented on. However, an effective alternative way of reaching this geographically and numerically sparse group of valuable doctors, of whom there is no formal national register, is challenging. The data presented by respondents is subjective, and potentially open to bias either in favour of operative experience, or indeed in hypothetical willingness to provide training, when financial implications have not been formulated. Ideally, the level of surgical training should be correlated to clinical outcome, however this is fraught with its own difficulties. The current paper serves as an initial discussion, hopefully leading to further studies.

The data from this survey have identified an appetite among respondents to take advantage of this shift in surgical practice to provide surgical training in this setting (see Results and table 2). There is a particular appetite for the training of junior surgical trainees, and prospective GPwSI's, which would be a useful addition to dwindling surgical opportunities within hospital surgery. ${ }^{9}$ However, there is significant heterogeneity in terms of prior surgical experience and formal surgical qualifications among members of the ASPC, a self-selected group with an interest in expanding surgical practice and training within the community. This raises significant issues around quality assurance of those providing training and occurs at a time when increasing importance is being placed on formal accreditation as a surgical trainer. ${ }^{15}$

When interpreting the data and its implications, it is important to note that there appear to be two distinct groups within community-based surgery: those who were surgical trainees or consultants and subsequently decided on a career in general practice, and those who had always been general practitioners and chose to perform surgery as part of their contractual workload. An expanding third group also exists, consisting of subcontracted NHS surgical consultants, but this survey did not gather data from this group, so it cannot be commented on.

In order to practise as a consultant surgeon within the $\mathrm{NHS}$, a doctor must undergo rigorous clinical and technical training, totalling a minimum of 10 years of postgraduate posts, including competitive entry after both foundation training and core surgical training. They must also pass two rigorous tests of surgical knowledge, by way of the Membership and Fellowship examinations of the Royal Colleges of Surgery (MRCS and FRCS). This demonstration of knowledge is coupled with continual assessment throughout training by both discussion of cases and direct observation of technical skills, all documented formally, and annually assessed to ensure adequate performance during training. The surgical training pathways and curricula are devised and quality assured by the Joint Committee on Surgical Training, who takes overall responsibility for the training programmes in each surgical specialty. Each training unit is required to provide multiple opportunities for trainees to meet the learning objectives set out by the curriculum. Furthermore, trainees are required to undertake a number of courses to supplement their technical and non-technical skills, including Basic Surgical Skills (BSS), Advanced Trauma Life Support (ATLS), Management/Leadership and teaching courses. Clinical governance principles within secondary care also mandate that serious surgical complications are scrutinised in regular morbidity and mortality meetings.

As an independent surgical consultant, outcomes are subject to scrutiny both locally by audit, but also nationally, following the recent publication of surgeon-specific outcomes. ${ }^{16}{ }^{17}$ Although this is not mandatory, penalties are imposed on those who do not participate in this process. ${ }^{18}$ Ongoing practice is also subject to peer surgical assessment via the process of revalidation. It is by this rigorous process of training and ongoing assessment that patients can gain trust in the abilities of those performing surgical procedures on them.

Practice in primary care is subject to revalidation mechanisms, and contractual morbidity audit. Although formal training in general practice is quality assured, such processes are not currently present to assure ability, outcomes or patient safety within the GPwSI in surgery system. While other GPwSI fields have an established framework for accreditation and revalidation overseen by the RCGP, ${ }^{19}$ surgery does not. However, the ASPC is keen to improve training availability in the community and has initiated discussions with the Royal College of Surgeons of England. GPwSI's practising surgery are responsible for assessing their own technical proficiency, local mechanisms for audit, identifying their learning needs and adherence to the GMC's Good Medical Practice guidance.

There is evidence from the dermatological literature raising concerns about the higher rate of incomplete excision in skin cancer when performed in the community by GPwSI's, ${ }^{20}{ }^{21}$ with little evidence that such procedures are cost-effective. ${ }^{3}$ One previous study has used such clinicopathological outcome analysis to determine educational requirements and guidelines for general practitioner skin surgery. ${ }^{22}$

The RCGP offers a 2-day course in minor surgery, which teaches basic surgical skills, suturing and excision of skin and subcutaneous lesions, some of which include direct observation of practical skills (DOPS) assessments. 
It is clear from our survey that, while it may be desirable for those practising surgical procedures within the community to have undergone rigorous surgical training, those who have represent a minority, and a significant proportion (46\%) have attended courses of less than 1 year or report no formal surgical qualifications. The implications for outcomes and on patient safety of this fact require serious consideration.

Training for minor surgery in the general practice setting has previously been reported as being in need of improvement, with nearly half of respondents to one regional survey $(43 \%)$ considering their training to be inadequate and $56 \%$ believing that assessment of technical competence by a hospital consultant was desirable, ${ }^{23}$ although contemporaneous literature is lacking. Continuing surgical instruction for general practitioners has been supported in one study, demonstrating measurable increases in technical proficiency and competence, with a low rate of educational decay. ${ }^{24}$ Formalisation of such training programmes together with periodical reassessment would be an important step in ensuring GPwSIs' skills remained sufficient for delivering surgical training. It is important to note that within the results of this survey, while all but two respondents felt able to train a trainee in a single procedure, none felt able to train somebody in a wide breadth of procedures. Careful matching of trainers to trainee needs would therefore be required in a community setting. This contrasts with secondary care where a surgical consultant would be able to train in a large range of more minor procedures, and may also raise issues surrounding the efficiency of surgical training in primary care.

In addition to technical proficiency, it is also important to ensure that the facilities and standards for providing surgery in the community are of a suitable level to support the delivery of surgical training. There is a paucity of data relating to this in the community setting, although historically concerns have been raised about these issues. ${ }^{25}{ }^{26}$ More recently, The Health and Social Care Act (Regulated Activities) Regulations 2014 has defined minimum standards for such premises, ${ }^{27}$ and the CQC provides guidance on how to achieve these standards. ${ }^{28}$

With regard to audit of outcomes, the communitybased surgery outcomes audit (http://www.hscic.gov.uk/ cbsa) opened in 2013 as a voluntary tool to support accreditation, and to 'support re-accreditation, appraisal, revalidation and local contracting'. This will help to offer practitioners a method by which to prove their outcomes are safe and comparable to procedures performed in the secondary care sector. However, without data contribution being mandatory, it will potentially be open to selection bias in a similar manner to surgeonspecific outcomes in secondary care.

The ASPC aims to remedy this by encouraging members to perform their own audits, publish their results and attend meetings to share best practice. However, while this is laudable, membership is voluntary and arguably likely to be highly self-selected. It is therefore likely that there could be a significant number of unquantifiable, unmonitored procedures being performed outwith these proposed mechanisms. Membership to such societies, which provide infrastructure for safe practice and continued professional development must be seen as mandatory in GP revalidation processes. Further work should be performed within an unselected GP cohort to gain more generaliseable data regarding prior surgical training, outwith membership of the ASPC. ASiT has previously proposed a framework for the delivery of operative training for surgical trainees within the community setting. ${ }^{9}$ These recommendations focus around ensuring the quality assurance of surgical training in the community, while enabling release of surgical trainees from hospital duties in the current service-driven training system. The Royal Colleges of Surgery and General Practice could coalesce already existing mechanisms to remedy many concerns around surgical training in the community. The inclusion of what are traditionally secondary care-based surgical trainees into primary care settings must be sufficiently funded through relevant NHS and CCG-commissioned contracts.

Although these findings are specific to UK healthcare practice, the results may be of interest in other settings given the increasing proportions of surgical procedures being undertaken in the community internationally. ${ }^{29} 30$

\section{CONCLUSIONS}

High volume surgery with good outcomes has been described in the community, and under the same scrutiny that secondary care surgical practice and training undergoes, opportunities for obtaining surgical skills in the community exist. However, training among doctors undertaking surgical procedures in a community setting is highly varied. Self-assessed operative training competence is variable, and limited in the breadth of procedures that could be offered. A significant volume of surgical procedures are being undertaken in the community by general practitioners, with the capacity and appetite for some training of junior surgical trainees in this setting, providing appropriate standards are achieved and maintained, commensurate with current standards in secondary care.

Author affiliations
${ }^{1}$ The Association of Surgeons in Training, London, UK
${ }^{2}$ University of Birmingham, Birmingham, UK
${ }^{3}$ Queen Elizabeth Hospital, Birmingham, UK
${ }^{4}$ University College London, London, UK
${ }^{5}$ Royal Free Hospital, London, UK
${ }^{6}$ Saint John's Hospital, Livingston, West Lothian, UK
${ }^{7}$ Royal College of Surgeons of England, London, UK
${ }^{8}$ Department of Surgery, Institute of Clinical Sciences, Sahlgrenska Academy,
Gothenburg University, Göteborg, Sweden
${ }^{9}$ University of Leicester, Leicester, UK

Acknowledgements The Authors would like to thank Laurel Spooner, Vijay Kumar and the Council of the Association of Surgeons in Primary Care for their assistance in collecting the data within this Study. 
Contributors AJB designed the questionnaire. HJMF and JR collected the data, with help from the ASPC. VJG, JEFF and HJMF analysed the data. All authors conceived and designed the study. All authors were responsible for compiling the manuscript and approving the final article.

Funding This research received no specific grant from any funding agency in the public, commercial or not-for-profit sectors.

Competing interests All of the authors are surgical trainees and elected members of the Council of the Association of Surgeons in Training (Registered Charity No. 274841), http://www.asit.org.

Provenance and peer review Not commissioned; externally peer reviewed.

Data sharing statement Respondent level data is available from the corresponding author at fergusonh@doctors.org.uk. Consent to data sharing was not obtained but the presented data are anonymised and risk of identification is low.

Open Access This is an Open Access article distributed in accordance with the Creative Commons Attribution Non Commercial (CC BY-NC 4.0) license, which permits others to distribute, remix, adapt, build upon this work noncommercially, and license their derivative works on different terms, provided the original work is properly cited and the use is non-commercial. See: http:// creativecommons.org/licenses/by-nc/4.0/

\section{REFERENCES}

1. Department of Health. Our Health, Our Care, Our Say. 2006

2. Association of Surgeons in Primary Care (ASPC). aspc-uk.net. http:// www.aspc-uk.net/ (accessed 18 Dec 2014).

3. Taneja A, Singh PP, Tan JPL, et al. Efficacy of general practitioners with specialty interests for surgical procedures. ANZ J Surg 2014. Published Online First: 1 Jul 2014. doi:10.1111/ans.12721

4. George S, Pockney P, Primrose J, et al. A prospective randomised comparison of minor surgery in primary and secondary care. The MiSTIC trial. Health Technol Assess 2008:12:iii-iv, ix-38.

5. O'Cathain A, Brazier JE, Milner PC, et al. Cost effectiveness of minor surgery in general practice: a prospective comparison with hospital practice. Br J Gen Pract 1992;42:13-17.

6. Dhumale R, Tisdale J, Barwell N. Over a thousand ambulatory hernia repairs in a primary care setting. Ann R Coll Surg Engl 2010;92:127-30.

7. Dhumale R. Feasibility study of hernia surgery in a general practice setting. Br J Gen Pract 2004;54:604-7.

8. van Dijk CE, Verheij RA, Spreeuwenberg P, et al. Minor surgery in general practice and effects on referrals to hospital care: observational study. BMC Health Serv Res 2011;11:2.

9. Gokani VJ, Ferguson HJM, Fitzgerald JEF, et al. Surgical training in primary care: consensus recommendations by the Association of Surgeons in Training. Int $J$ Surg 2014;12(Suppl 3):S1-4.

10. Jones R, Rosen R, Tomlin Z, et al. General practitioners with special interests: evolution and evaluation. J Health Serv Res Policy 2006;11:106-9.
11. Nocon A, Leese B. The role of UK general practitioners with special clinical interests: implications for policy and service delivery. $\mathrm{Br} \mathrm{J}$ Gen Pract 2004;54:50-6.

12. Fitzgerald JEF, Giddings CEB, Khera G, et al. Improving the future of surgical training and education: consensus recommendations from the Association of Surgeons in Training. Int J Surg 2012;10:389-92.

13. Darzi A. High quality care for all. NHS next stage review final report. 2008. http://www.dh.gov.uk/prod_consum_dh/groups/dh_ digitalassets/@dh/@en/documents/digitalasset/dh_085828.pdf (accessed 10 March 2015)

14. Greenaway D. ed. Securing the Future of Excellent Patient Care. shapeoftraining.co.uk. http://www.shapeoftraining.co.uk/static/ documents/content/Shape_of_training_report_Final_Report.pdf_ 53900462.pdf (accessed 5 Nov 2013).

15. Mcllhenny C, Pitts D. Standards for Surgical Training. 2014.

16. Alderson D, Cromwell D. Publication of surgeon-specific outcomes. Br J Surg 2014;101:1335-7.

17. Radford PD, Derbyshire LF, Shalhoub J, et al. Publication of surgeon specific outcome data: a review of implementation, controversies and the potential impact on surgical training. Int J Surg 2015;13C:211-16.

18. Surgeons told to publish deaths. The Sunday Times. thesundaytimes.co.uk. http://www.thesundaytimes.co.uk/sto/news/ uk news/Health/article1484543.ece (accessed 22 Dec 2014).

19. Practitioners RCOG. GP with a Special Interest (GPwSI) accreditation. rcgp.org.uk. http://www.rcgp.org.uk/clinical-andresearch/clinical-resources/gp-with-a-special-interest-gpwsiaccreditation.aspx (accessed 18 Dec 2014).

20. Salmon P, Mortimer N, Rademaker M, et al. Surgical excision of skin cancer: the importance of training. Br J Dermatol 2010;162:117-22.

21. Murchie P, Delaney EK, Thompson WD, et al. Excising basal cell carcinomas: comparing the performance of general practitioners, hospital skin specialists and other hospital specialists. Clin Exp Dermatol 2008;33:565-71.

22. Cox NH, Wagstaff R, Popple AW. Using clinicopathological analysis of general practitioner skin surgery to determine educational requirements and guidelines. BMJ 1992;304:93-6.

23. Thompson AM, Park KG, Kelly DR, et al. Training for minor surgery in general practice: is it adequate? $J R$ Coll Surg Edinb 1997;42:89-91.

24. Collins AM, Ridgway PF, Hassan MSU, et al. Surgical instruction for general practitioners: how, who and how often? J Plast Reconstr Aesthet Surg 2010;63:1156-62.

25. Finn L, Crook S. Minor surgery in general practice-setting the standards. J Public Health Med 1998;20:169-74.

26. Zoltie N, Hoult G. Adequacy of general practitioners' premises for minor surgery. BMJ 1991;302:941-2.

27. The Health and Social Care Act 2008 (Regulated Activities) Regulations 2014. Queen's Printer of Acts of Parliament.

28. Guidance for providers on meeting the fundamental standards and on CQC's enforcement powers: Consultation. http://www.cqc.org.uk/ sites/default/files/20140725_fundamental_standards_and enforcement_consultation_final.pdf (accessed 1 Jan 2015).

29. Serra M, Arévalo A, Ortega $C$, et al. Minor surgery activity in primary care. JRSM Short Rep 2010;1:36.

30. Arribas Blanco JM, Rodríguez Salceda I, Mena Mateo JM, et al. Minor surgery in the family physician's office. Description of one year's experience. Aten Primaria 1996;17:142-6. 